\title{
Synthesis and Li Electroactivity of MnS/Carbon Nanotube Composites
}

\author{
Gwang-Hee Lee, Kyung-Mi Min, and Dong-Wan Kim ${ }^{\dagger}$
}

Department of Energy Systems Research, Ajou University, Suwon 443-749, Korea

(Received September 5, 2013; Revised November 2, 2013; Accepted November 11, 2013)

\section{$\mathrm{MnS}$ / 카본나노튜브 복합체의 합성과 리튬 전기화학적 거동 \\ 이광희 · 민경미 · 김동완 ${ }^{\dagger}$ \\ 아주대학교 에너지시스템학과 \\ (2013년 9월 5일 접수 ; 2013년 11월 2일 수정 ; 2013년 11월 11일 채택)}

\begin{abstract}
A simple synthetic process is demonstrated for the preparation of MnS/carbon nanotube (CNT) composites for Li ion battery electrodes. CNTs were initially treated using a strong acid solution to generate carboxylate ions (-COO ${ }^{-}$) on their surfaces. The MnS/ CNT composites were synthesized by a polyvinyl-pyrrolidone-assisted hydrothermal method in the presence of as-functionalized CNTs. The phase and morphology of the MnS/CNT composites and pure MnS microspheres were characterized using X-ray diffraction and high-resolution transmission electron microscopy. Furthermore, the Li electroactivity levels of the MnS/CNT composites and $\mathrm{MnS}$ microspheres were investigated using cyclic voltammetry and galvanostatic cycling. The MnS/CNT composite electrodes showed higher specific capacities exceeding $365 \mathrm{~mA} \mathrm{~h} \mathrm{~g}^{-1}$ at a C/10 current rate and enhanced cyclic performance compared to pure $\mathrm{MnS}$ microspheres.
\end{abstract}

Key words: MnS microspheres, Functionalized CNT, Hydrothermal process, Li ion battery

\section{1. 서 론}

현재 스마트폰, 스마트패드 등의 소형 모바일 기기는 급격한 발달을 이루고 있지만 구동전원인 리튬이온 이차 전지가 여전히 소형 기기의 부피와 무게의 많은 부분을 차지하고 있다. 이에 따라서 리튬이온 이차전지는 초소형 및 초경량화와 더불어 고성능화된 특성을 요구하고 있다. 현재 상용화된 graphite계 음극소재는 무게를 가볍게 할 수 있으나 낮은 용량 (graphite 이론용량: $372 \mathrm{~mA} \mathrm{~h} \mathrm{~g}^{-1}$ )의 한계로 인하여 이를 대체하기 위한 연구가 매우 활발하 게 이루어지고 있다. 따라서 고용량 특성 구현이 가능한 산화물을 중심으로 한 전이금속 화합물에 대한 상당한 연 구가 진행되고 있으며, 이들의 향상된 전기화학적 특성을 보고하는 사례들이 급격히 증가하고 있다. ${ }^{1-3)}$

최근에는 $\mathrm{FeS}, \mathrm{FeS}_{2}, \mathrm{CoS}_{2}, \mathrm{NiS}_{2}$ 등의 전이금속 황화물 이 고용량 특성의 음극소재로 주목 받고 있다. ${ }^{4)}$ 음극소 재로서, 전이금속 황화물의 리틈이온 반응은 전이금속 산 화물과 유사한 전환반응으로 인하여, 높은 이론용량을 갖

\footnotetext{
${ }^{\dagger}$ Corresponding author : Dong-Wan Kim

E-mail : dwkim@ajou.ac.kr

Tel : +82-31-219-2468 Fax : +82-31-219-3248
}

는다 $\left(M S+2 \mathrm{Li}^{+}+2 \mathrm{e}^{-} \leftrightarrow \mathrm{Li}_{2} \mathrm{~S}+M, M\right.$ : 전이금속 $)$ 하지만, 전 이금속 황화물은 전이금속 산화물과 마찬가지로 충.방전 시에 전환반응을 하면서 큰 부피 변화가 초래되며, 도전 제의 접촉을 약화시켜 전자의 흐름을 방해하기 때문에 충.방전 사이클 특성의 저해 요소가 된다. 또한 방전반응 시에 나타나는 $\mathrm{Li}_{2} \mathrm{~S}$ 는 매우 낮은 전기 전도성을 갖고 있 기 때문에 전이금속들이 충전 시에 본래의 형태인 전이 금속 황화물 형태로 완벽하게 돌아오지 못한다. 따라서 층.방전 사이클 횟수가 증가함에 따라서 급격한 용량의 감소와 함께 낮은 충.방전 효율을 보인다. 이러한 낮은 전 기 전도성과 사이클 특성 저하를 보완하기 위한 몇 가지 시도들이 있다. 나노분말, 나노로드, 나노선과 같은 나노 구조체 합성은 전이금속 산화물 및 황화물계 음극소재의 물성을 향상시키는 것으로 보고되고 있다. ${ }^{1,9,10)}$ 또한 고전 도성 확보를 위해 카본 코팅을 하거나 다공성 카본 또는 카본 나노튜브 (CNT), graphene 등과 복합체를 형성시키 는 연구도 진행되고 있다. ${ }^{2,7,11)}$

본 연구에서는 전이금속 황화물 중에서 리튬이온 이차 전지의 음극소재로 많은 보고가 되어있지 않은 $\mathrm{MnS}$ 를 다 루었다. 우선적으로, $\mathrm{MnS}$ microspheres $(\mathrm{MnS} \mathrm{MSs})$ 를 수 열합성법을 이용, 매우 균일한 분말을 합성하였으며, 더 
불어 $\mathrm{MnS}$ 의 낮은 전기 전도성을 고려하여 $\mathrm{CNT}$ 와의 복 합체를 형성하였다. 결과적으로 합성된 $\mathrm{MnS} / \mathrm{CNT}$ 복합체 는 hollow sphere의 형태를 갖는다. 합성된 $\mathrm{MnS} M \mathrm{MSs}$ 와 $\mathrm{MnS} / \mathrm{CNT}$ hollow spheres $(\mathrm{MnS} / \mathrm{CNT} \mathrm{HSs})$ 들은 순환전압 전류 $(\mathrm{CV}$, cyclic voltammetry) 테스트를 통하여 리튬이온 과의 전기화학 반응 분석과 정전류 테스트를 통하여 충. 방전 사이클 및 용량 특성 평가를 진행하였다. 또한 electrochemical impedance spectroscopic (EIS) 특정을 통 하여 전하 이동 반응을 비교하였다.

\section{2. 실험방법}

\subsection{MnS microspheres의 합성}

$120 \mathrm{~mL}$ 의 증류수에 $3 \mathrm{mmol}$ 의 $\mathrm{MnCl}_{4} \cdot 4 \mathrm{H}_{2} \mathrm{O}$ (SigmaAldrich, > 98.0\%), $12 \mathrm{mmol}$ 의 L-cysteine $\left(\mathrm{HSCH}_{2} \mathrm{CH}\left(\mathrm{NH}_{2}\right)\right.$ $\mathrm{CO}_{2} \mathrm{H}$, Alfa Aesar, $98+\%$ )과 $1.8 \mathrm{~g}$ 의 polyvinyl-pyrrolidone (PVP, Sigma-Aldrich)을 용해시켰다. 준비된 용액은 $300 \mathrm{~mL}$ 용량의 수열합성 반응기에 옮겨서 $180^{\circ} \mathrm{C}$ 에서 8 시간동안 교반하면서 반응시켰다. 반응 종료 후 반응기 내에 냉각 수를 흘려주어 용액을 빠르게 냉각시켰다. 냉각된 용액은 원심분리기를 이용하여 무수에탄올에 의해 3회 정도 세 척한 후에, $60^{\circ} \mathrm{C}$ 의 오븐에서, 12 시간동안 진공 분위기 건 조를 시행하였다.

\subsection{MnS/CNT hollow spheres의 합성}

$\mathrm{H}_{2} \mathrm{SO}_{4}$ 와 $\mathrm{HNO}_{3}$ 을 $3: 1$ 의 비율로 섞은 용액에 $2 \mathrm{~g}$ 의 다 층벽 카본나노튜브 (Multi-Walled Carbon Nanotubes, Hanwha Nanotech Co., Ltd., Korea)를 넣고 30분동안 교반시켜 표 면개질을 하였다. CNT 용액은 여과한 후에 무수에탄올로 세척하였다. 표면개질 된 CNT $0.04 \mathrm{~g}$ 을 $120 \mathrm{ml}$ 의 증류수 에 넣고 1 시간 동안 초음파 처리하여 분산시켰다. 그 후, $\mathrm{MnS} / \mathrm{CNT}$ hollow spheres는 $\mathrm{MnS} \mathrm{MSs}$ 의 합성과 동일한 단계로 합성하였다.

\section{3. 특성 평가}

합성된 분말들은 X-선 회절 (XRD; Model: $\mathrm{D} / \mathrm{max}-2500$, Rigaku, Japan)을 통하여 결정구조를 분석하였으며, 투과 전자현미경 (TEM; Model:JEM-3000F, JEOL, Japan)과 전 계방출 주사전자현미경 (FE-SEM, Field emission scanning electron microscopy, JSM-6700F, JEOL, Tokyo, Japan)을 이용하여 형상 또는 결정상을 확인하였다. 열중량분석기 (TGA, Thermogravimetric analysis, DTG-60H, Shimadzu, Kyoto, Japan)를 통하여 CNT의 정량 분석을 실시하였다. 전기화학적 특성 평가는 합성된 분말들의 리튬 전기화학 반응성을 알아보기 위해 반쪽 전지를 이용하여 전기화학 적 특성 평가를 수행하였다. 측정 시 사용된 전극의 제작 은 결합제 (PVDF)와 도전제 (Super-P)가 각각 $70: 15: 15$
의 비율로 혼합된 분말을 1-methyl-2-pyrrolidinone (NMP; Sigma-Aldrich, $95 \%$ )에 분산시켜 슬러리로 만든 후, 구리 호일에 고르게 도포하고 건조하였다. 또한, 리튬 금속을 음극으로 사용하고 제조된 전극을 양극으로 적용하여 $\mathrm{Ar}$ 분위기의 글로브 박스 안에서 전지를 조립하였다. 조립된 전지들은 $0.01 \mathrm{~V} \sim 3 \mathrm{~V}$ 까지의 작동 전압 하에서 순환전압 전류 및 정전류 방식의 측정을 진행하였다. 또한 전기화 학 시험 분석기 (Ivium-n-Stat, Ivium Technologies, Eindhoven, Netherlands)를 사용하여 $10 \mathrm{mV}$ 의 교류전압을 인가하여 $100 \mathrm{kHz}$ 부터 $10 \mathrm{mHz}$ 까지의 주파수 범위에서 $\mathrm{EIS}$ 측정을 하였다.

\section{3. 결과 및 고찰}

본 연구에서 합성된 $\mathrm{MnS} \mathrm{MSs}$ 와 $\mathrm{MnS} / \mathrm{CNT} \mathrm{HSs}$ 의 결 정상을 파악하기 위하여, $\mathrm{XRD}$ 패턴을 분석하였다. Fig. 1 의 XRD 패턴에서 보는 것과 같이, 합성된 분말들은 각 각 $\gamma-\mathrm{MnS}$ [JCPDS No. 40-1289]의 결정 패턴과 대부분 일치하는 것을 확인 할 수 있었으며, 약간의 $\alpha-\mathrm{MnS}$ 를 포 함하고 있음을 확인하였다.

합성된 $\mathrm{MnS} \mathrm{MSs}$ 의 형태를 파악하기 위하여 FE-SEM 으로 관찰을 실시하였다 (Fig. 2(a)와 (b)). 약 $1 \mu \mathrm{m}$ 정도 의 직경을 갖고 있는 매우 균일한 구형체를 이루고 있으 며 표면 위에는 직경이 약 $100 \mathrm{~nm}$ 정도의 균일한 형태를 갖는 나노로드들이 수직 배열되어 있다. 이들의 미세 구 조를 관찰하기 위하여 TEM 분석을 실시하였다. Fig. 2(c) 의 저배율 $\mathrm{TEM}$ 이미지에서 보는 것과 같이, $\mathrm{MnS} \mathrm{MSs}$ 는 매우 균일한 크기와 형태를 갖고 있으며 구형체의 표

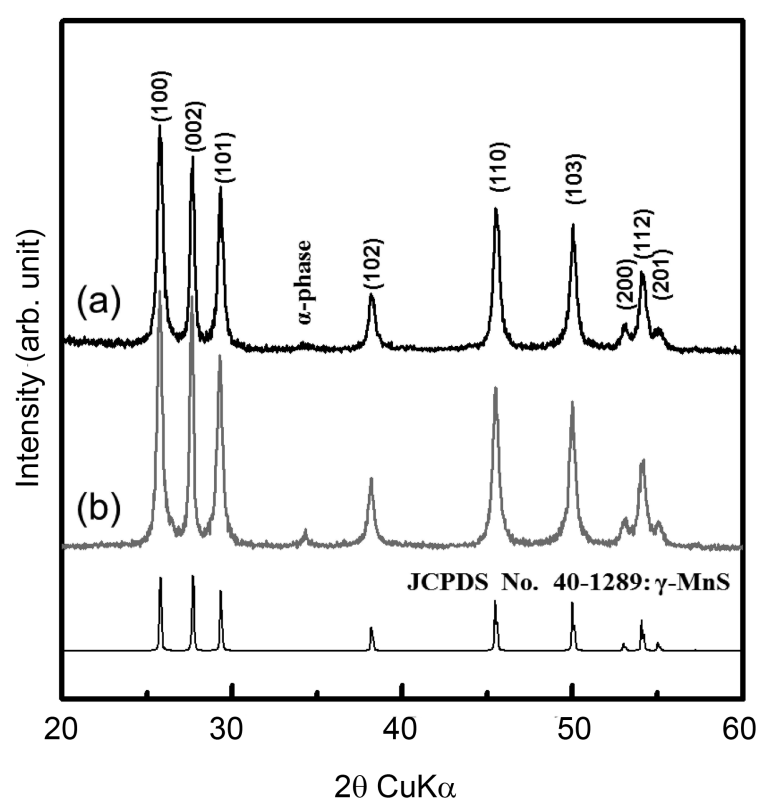

Fig. 1. XRD patterns of (a) MnS/CNT HSs and (b) MnS MSs. 

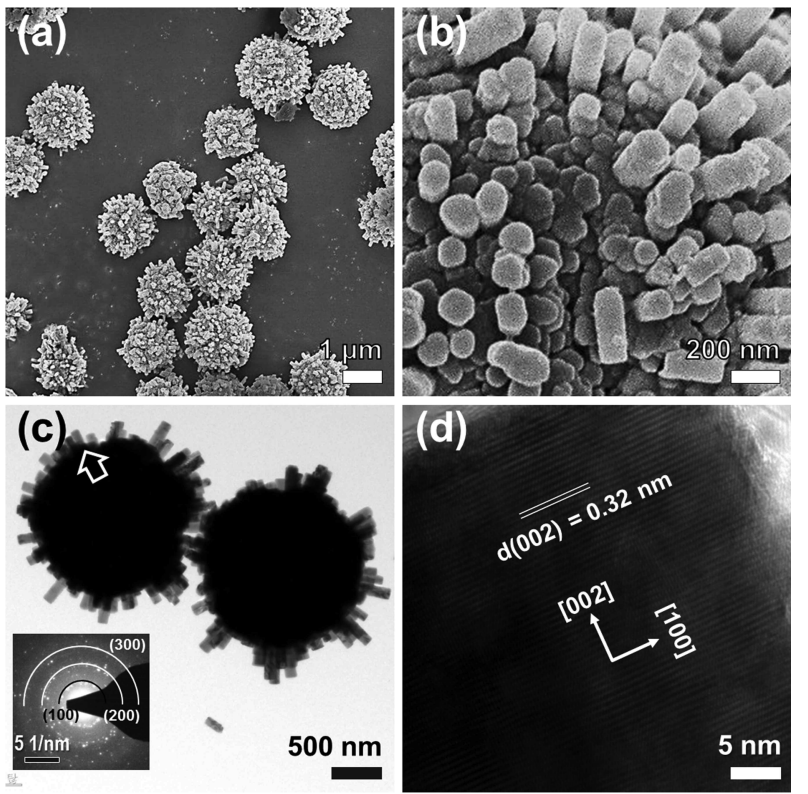

Fig. 2. Morphological analysis of MnS MSs using FE-SEM and TEM: (a) Low-magnication FE-SEM image, (b) high-magnication FE-SEM image, (c) Low-magnication TEM image, and (d) HR TEM iamge. The insets in (c) shows corresponding SAED patterns.

면 위에서 나노로드들이 Fig. 2(a)와 (b)에서와 같이 수직 배열되어 있는 것을 관찰할 수 있다. 이들의 selected area electron diffraction (SAED) 패턴을 분석한 결과, $\mathrm{XRD}$ 패 턴의 분석과 일치하며 $\gamma-\mathrm{MnS}$ 의 (100), (200)과 (300) 면들 의 면간 거리와 잘 일치함을 알 수 있다 (Fig. 2(c) inset). 더욱 정밀한 분석을 위하여 고분해능 TEM (HR-TEM)으 로 나노로드 부분을 관찰하였다 (Fig. 2(d)). 나노로드 부 분은 Fig. 2(c)의 화살표 부위를 따른다. 나노로드의 면간 거리를 측정한 결과 $0.32 \mathrm{~nm}$ 로 (002) 면과 일치하는 것을 확인 할 수 있으며 c-axis 방향을 따라 성장하는 것을 관 찰 할 수 있다.

Fig. 3은 $\mathrm{MnS} / \mathrm{CNT} \mathrm{HSs}$ 의 FE-SEM 이미지와 TGA 그 래프이다. Fig 3(a)의 저배율 FE-SEM 이미지를 보면 직 경이 $5 \mu \mathrm{m}$ 이하의 균일한 구형체를 이루고 있으며 내부 가 비어있는 구형체임을 관찰 할 수 있다. Fig. 3(b)는 $\mathrm{MnS} /$ CNT HSs의 고배율 FE-SEM 이미지이다. MnS/CNT HSs 의 내부에도 나노입자와 CNT 다발이 존재하고 있으며 외 부는 매우 균일하게 나노로드들이 일정한 방향으로 배열 되어 있는 것을 알 수 있다. 또한 $\mathrm{MnS} / \mathrm{CNT} \mathrm{HSs}$ 의 나노 로드 사이에는 $\mathrm{CNT}$ 가 위치하고 있음을 확인할 수 있다 (Fig. 3(c)). 결과적으로 $\mathrm{MnS} / \mathrm{CNT} \mathrm{HSs}$ 는 hollow 구형체이 며 껍질 부분에서 나노로드와 $\mathrm{CNT}$ 가 매우 균일하고 고 밀도로 배열된 구조체이다. 이러한 hollow 구조체의 형성 은 PVP의 역할이 매우 중요하다. ${ }^{12,13)} \mathrm{PVP}$ 는 친수성과 소 수성을 모두 포함하고 있는 고분자이며 액상 기반의 합
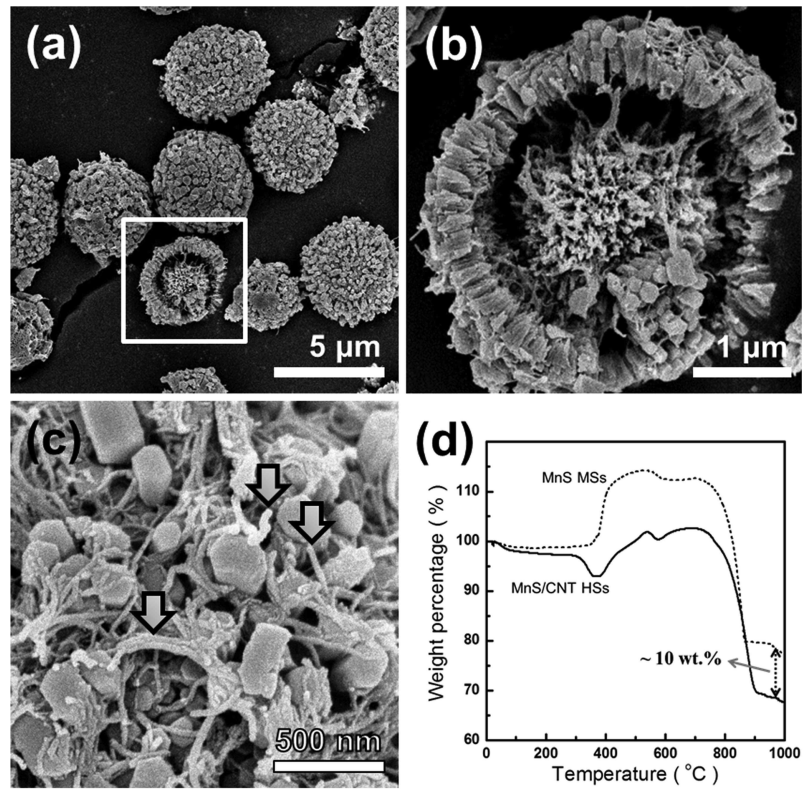

Fig. 3. Charaterization of MnS/CNT HSs: (a,b) Low- and (c) high-magnication FE-SEM images, and (d) TGA curves of MnS/CNT HSs and MnS MSs.

성에서 다양한 형태의 구조체를 형성할 수 있다. 다양한 형태의 구조체 형성이 가능한 이유는 PVP가 steric stabilizer 또는 capping agent의 역할을 하여 불균일 응집을 제어하 기 때문이다. 또한 soft template의 역할을 하기 때문에 hollow 구조체를 형성하는 것이 가능하다. 본 실험에서 합성된 $\mathrm{MnS} /$ $\mathrm{CNT} \mathrm{HSs}$ 의 경우에는 용액 속에서 PVP가 spherical micelle 로 자기 조립하여 $\mathrm{Mn}$ nuclei를 spherical micelle의 표면에 흡착하여 hollow 구조체를 형성했을 것으로 추측할 수 있 다. $\mathrm{PVP}$ 를 이용한 $\mathrm{MnS} \mathrm{MSs}$ 와 $\mathrm{MnS} / \mathrm{CNT} \mathrm{HSs}$ 의 각 단 계별 구조형성 과정을 Fig. 4에 나타내었다. $\mathrm{MnS} \mathrm{MSs}$ 의 경우 같은 양의 $\mathrm{PVP}$ 로 같은 조건에서 합성되었지만 $\mathrm{FE}-$ $\mathrm{SEM}$ 이미지만으로 hollow 구조체임을 확인할 수 없었 다. 하지만 $\mathrm{MnS} / \mathrm{CNT} \mathrm{HSs}$ 의 경우에 $\mathrm{CNT}$ 가 첨가되면서 $\mathrm{MnS} / \mathrm{CNT} \mathrm{HSs}$ 의 표면에 균열이 많은 것을 Fig. 3(a)에서 확인할 수 있으며 hollow 구조체인 것을 쉽게 확인할 수 있다. $\mathrm{MnS} / \mathrm{CNT} \mathrm{HSs}$ 에서 $\mathrm{CNT}$ 는 산에 의하여 표면개질 이 되어 카르복실기가 형성되고 음전하를 띄게 된다. 따 라서 많은 양의 $\mathrm{Mn}^{4+}$ 이온을 흡착할 수 있을 뿐만 아니 라 망간 화합물을 단분산된 형태로 형성시킬 수 있다. 이 는 $\mathrm{CNT}$ 또는 $\mathrm{MnS}$ 가 각각 응집체를 이루는 것을 막아주 어 고른 분포를 할 수 있게 도와준다. ${ }^{14)}$ 따라서 PVP와 표 면개질된 $\mathrm{CNT}$ 가 상호 작용하여 $\mathrm{MnS} / \mathrm{CNT} \mathrm{HSs}$ 의 껍질에 위치한 나노로드 사이에서 $\mathrm{CNT}$ 네트워크를 형성하게 한 것으로 판단된다. Fig. 3(d)는 합성된 $\mathrm{MnS} / \mathrm{CNT} \mathrm{HSs}$ 분말 에서 $\mathrm{CNT}$ 의 정량을 위한 $\mathrm{TGA}$ 그래프이다. 대기 분위기 에서의 온도에 따른 무게 감량을 분석한 결과, $\mathrm{MnS} / \mathrm{CNT}$ 


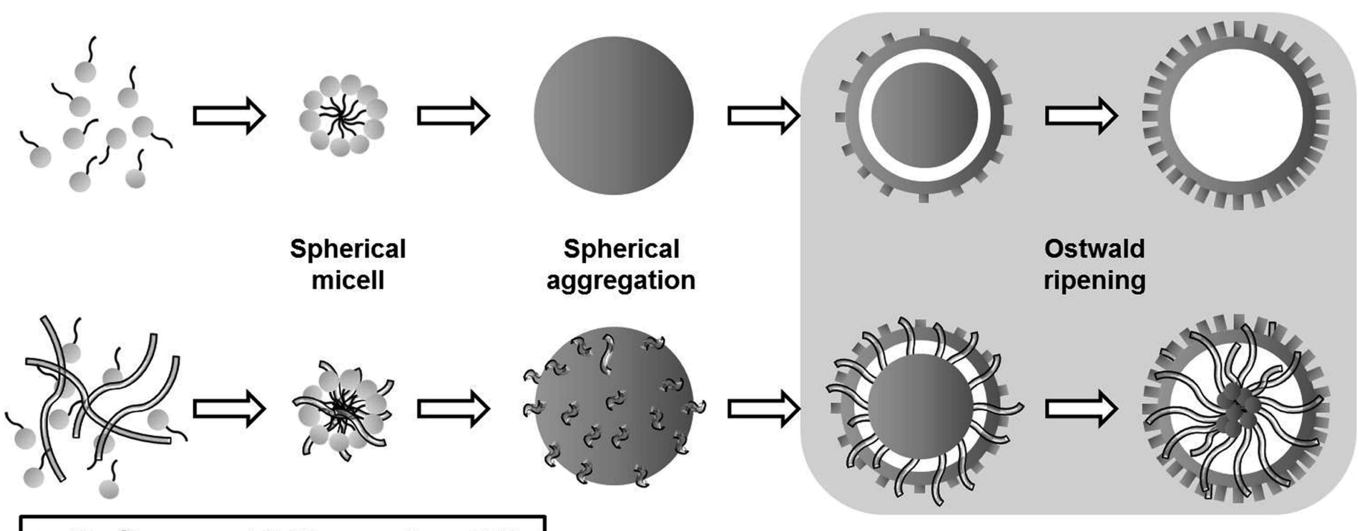

$$
\mathrm{Mn}^{2+} \sim \mathrm{PVP} \quad \approx \mathrm{CNT}
$$

Fig. 4. Schematic illustration of the synthesis steps forming MnS MSs and MnS/CNT HSs.

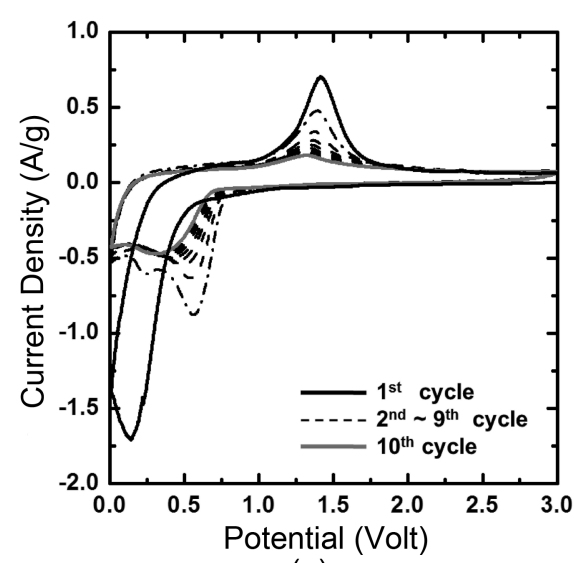

(a)

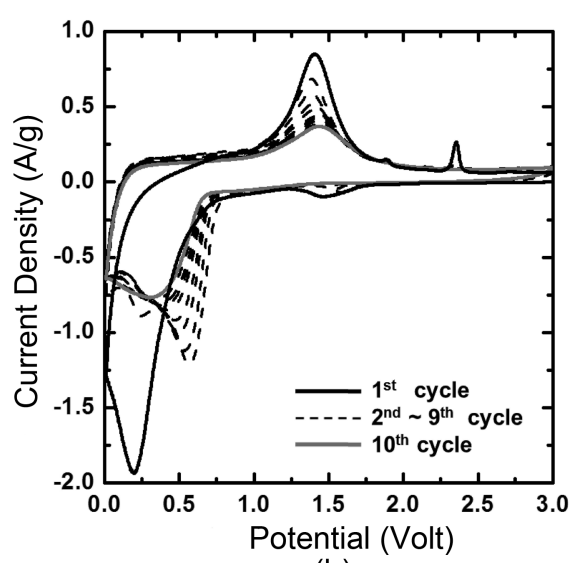

(b)

Fig. 5. Cyclic voltammetries of (a) MnS MSs and (b) MnS/CNT HSs electrodes.

$\mathrm{HSs}$ 의 무게 감량은 $\mathrm{MnS} \mathrm{MSs}$ 의 무게 감량에 비교하여 $10 \mathrm{wt} \%$ 가 더 크다. 이를 통하여 $\mathrm{MnS} / \mathrm{CNT} \mathrm{HSs}$ 가 $10 \mathrm{wt} \%$ 의 $\mathrm{CNT}$ 를 포함하고 있다는 것을 알 수 있다.

합성된 $\mathrm{MnS} \mathrm{MSs}$ 와 $\mathrm{MnS} / \mathrm{CNT} \mathrm{HSs}$ 전극의 리튬 전기 화학반응성을 평가하기 위해 순환전압법 (cyclic voltammetry, $\mathrm{CV}$ ) 분석을 진행하였다(Fig. 5). 분석된 $\mathrm{CV}$ 그래프는 $0.1 \mathrm{mV} \mathrm{s}^{-1}$ 의 주사속도로 $0.01 \sim 3 \mathrm{~V}$ 의 전압 범위에서 10 사 이클 반복하여 측정하였다. $\mathrm{CV}$ 그래프에 나타난 것처럼, $\mathrm{MnS} \mathrm{MSs}$ 와 $\mathrm{MnS} / \mathrm{CNT} \mathrm{HSs}$ 전극을 비교하면 산화·환원 peak의 위치는 유사하다. 하지만 $\mathrm{MnS} / \mathrm{CNT} \mathrm{HSs}$ 전극이 $\mathrm{MnS} \mathrm{MSs}$ 전극보다 peak가 크고, 첫 번째 사이클의 산화 peak는 더욱 명확하게 나타난다. $\mathrm{MnS} / \mathrm{CNT} \mathrm{HSs}$ 전극의 경우에는, 첫 번째 사이클을 진행하는 동안 0.18 과 $1.46 \mathrm{~V}$ 에서 리튬이온이 삽입되는 환원 peak가 나타났다. 그 중 $0.18 \mathrm{~V}$ 에서 나타난 큰 환원 peak는 고체전해질계면 (solid electrolyte interface, $\mathrm{SEI}$ ) 층이 형성되면서 나타나는 현상 이다. $1.46 \mathrm{~V}$ 부근에서 나타나는 환원 peak은 $\gamma-\mathrm{MnS}$ 결정 격자에 $\mathrm{Li}^{+}$가 삽입되어 $\mathrm{Li}_{\mathrm{x}} \mathrm{MnS}$ 를 형성하는 것이다. 산화 peak의 경우에는, $1.40,1.88$ 와 $2.35 \mathrm{~V}$ 의 세 개의 peak들이 나타난다. 두 번째 사이클 후에는, 이들 산화 peak 중에 서 $1.40 \mathrm{~V}$ 부근의 산화 peak를 제외하고 모두 사라진다. 또한 $1 \mathrm{~V}$ 이하의 환원 peak의 경우에는, SEI 층에 의한 환원 peak가 사라지고 0.23 과 $0.56 \mathrm{~V}$ 의 두 개의 환원 peak 가 나타난다. 이러한 $\mathrm{CV}$ 측정 결과는 이전에 보고된 경 향과 유사한 형태임을 확인하였다. ${ }^{15)}$

앞서 언급한 것처럼, 전이금속 황화물들의 경우 리튬이 온과의 전환반응 메커니즘을 통해 용량 특성을 나타낼 수 있다. 일반적으로 $\mathrm{MnS}$ 의 경우에는 리튬이온과의 충 - 방 전 반응 간에 발생하는 반응은 아래의 식과 같이 나타낼 수 있으며 이를 바탕으로 계산된 이론용량을 통해 정전 류 측정 방식에서 주입하는 전류 밀도를 계산할 수 있다.

$$
\mathrm{MnS}+2 \mathrm{Li}^{+}+2 \mathrm{e}^{-} \leftrightarrow \mathrm{Mn}+\mathrm{Li}_{2} \mathrm{~S}
$$

Fig. 6는 $\mathrm{MnS} / \mathrm{CNT} \mathrm{HSs}$ 와 $\mathrm{MnS} \mathrm{MSs}$ 전극의 전압-비용 량에 따른 정전류 곡선을 나타낸 것이다. $0.01 \sim 3 \mathrm{~V}$ 사이 


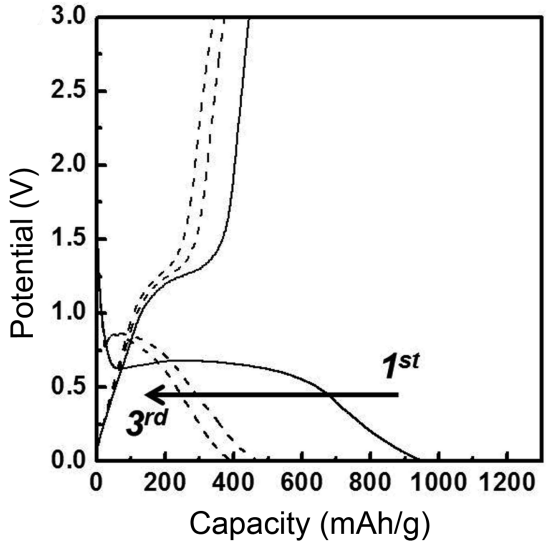

(a)

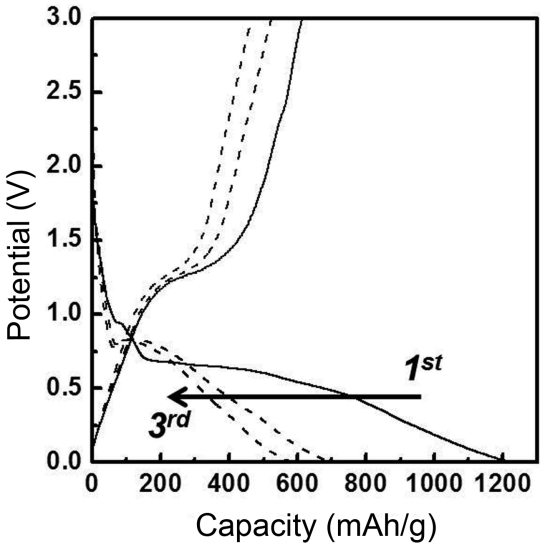

(b)

Fig. 6. Discharge-charge curves of (a) MnS MSs and (b) MnS/CNT HSs electrodes.

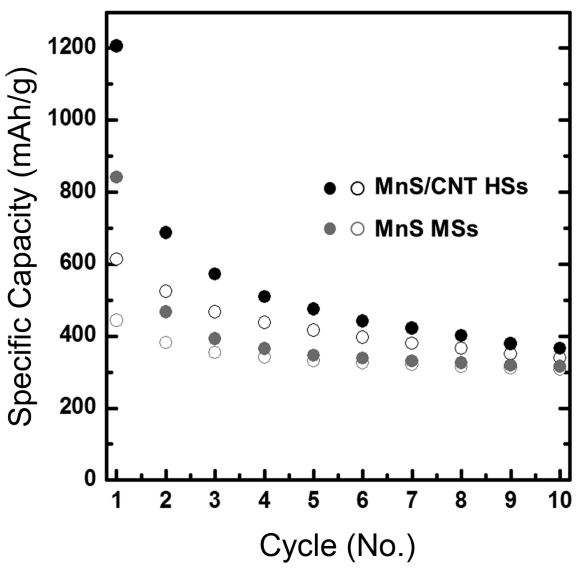

(a)
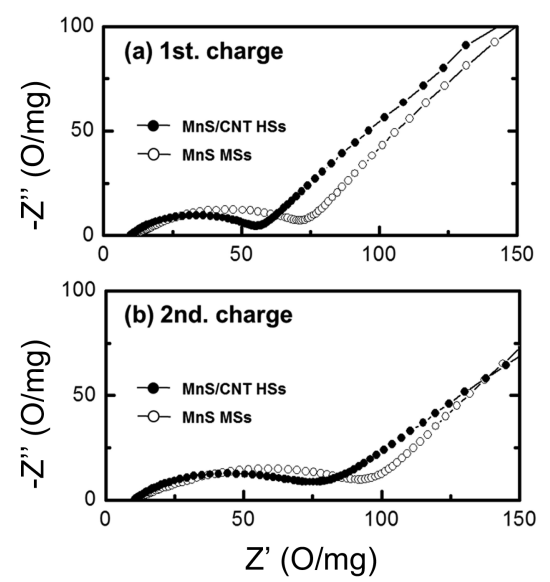

(b)

Fig. 7. (a) Comparison of the charge (open circle) and discharge (closed circle) capacities and (b) Nyquist plots collected at the $1^{\text {st }}$ and $2^{\text {nd }}$ charged state of of MnS MSs and MnS/CNT HSs electrodes.

의 작동 전압 구간에서 $\mathrm{C} / 10$ 의 전류 밀도로 $\left(61.6 \mathrm{~mA} \mathrm{~g}^{-1}\right.$, 이론용량 $=616 \mathrm{~mA} \mathrm{~h} \mathrm{~g}^{-1}$ ) 측정하였다. 첫 번째 방전 곡선 을 보면, $\mathrm{MnS} / \mathrm{CNT} \mathrm{HSs}$ 와 $\mathrm{MnS} \mathrm{MSs}$ 전극에서 약 0.6 $\mathrm{V}$ 에서 곡선이 평탄해진다. 이러한, 초기 비가역적인 용량 발생은 충·방전 사이클 진행간 형성되는 $\mathrm{SEI}$ 층의 형성 과 관련된다. 이 후 두 전극은 같은 경향을 보이면 충.방 전을 함을 그래프를 통해 알 수 있다.

Fig. 7(a)는 $\mathrm{MnS} / \mathrm{CNT} \mathrm{HSs}$ 와 $\mathrm{MnS} \mathrm{MSs}$ 전극의 충.방전 용량/사이클 그래프를 나타낸 것이다. $\mathrm{MnS} / \mathrm{CNT} \mathrm{HSs}$ 전 극이 $\mathrm{MnS} \mathrm{MSs}$ 전극보다 10 사이클 동안 사이클 용량 특 성이 비교적 우위에 있는 것을 확인할 수 있다. MnS/CNT $\mathrm{HSs}$ 전극의 경우에는 첫 번째 방전 용량이 $1205 \mathrm{~mA} \mathrm{~h} \mathrm{~g}^{-1}$ 을 나타냈다. 첫 번째 방전 용량과 충전 용량 사이에서 큰 비가역적인 용량의 차이를 확인할 수 있었으며, 이 후, 충·방전의 사이클이 진행되면서 용량의 감소가 점진적으로 발생했다. 열 번째 사이클의 방전 용량은 $365 \mathrm{~mA} \mathrm{hg}^{-1}$ 이다. $\mathrm{CV}$ 와 사이클 측정의 결과에서 보는 것과 같이 $\mathrm{MnS} / \mathrm{CNT}$
$\mathrm{HSs}$ 전극은 $\mathrm{MnS} \mathrm{MSs}$ 전극 보다 전기화학적 특성이 향 상된 것을 확인할 수 있다. 이는 고전도성의 $\mathrm{CNT}$ 의 첨가 에 의한 것으로 추측할 수 있다. 이를 명확하게 하기 위 하여 EIS 측정을 실시하였다. Fig. 7(b)에서 보여주는 Nyquist plot은 반쪽 전지를 이용하여 첫 번째와 두 번째 완전 방전 후의 결과이다. $\mathrm{MnS} / \mathrm{CNT} \mathrm{HSs}$ 전극의 첫 번째 와 두 번째 방전 후에 나타나는 고주파 영역에서의 반원 의 직경은 $\mathrm{MnS} \mathrm{MSs}$ 전극의 반원의 직경보다 작다. 이 결 과로, 고전도성의 $\mathrm{CNT}$ 의 첨가로 인하여 전극의 전기 전 도성이 향상되었음을 보여주고 있으며 $\mathrm{MnS} / \mathrm{CNT} \mathrm{HSs}$ 전 극의 향상된 전기화학적 특성을 보여줄 수 있다. 이상의 결과로 볼때, $\mathrm{MnS} / \mathrm{CNT} \mathrm{HSs}$ 는 $\mathrm{MnS} \mathrm{MSs}$ 에 비하여 초기 용량이 증가하였으나, 사이클 및 용량 특성이 크게 개선되 지 않은 결과를 보이고 있다. 이는 추후에 낮은 전기 전도 성을 갖는 $\mathrm{MnS}$ 의 이온 전도성을 향상시키기 위한 $\mathrm{CNT}$ 첨가 비율의 최적화, $\mathrm{MnS}$ 입자의 크기를 줄이거나 carbon coating 방법등이 추가로 고려되어야 할 것으로 판단된다. 


\section{4. 결 론}

본 논문에서는 PVP를 이용한 수열합성법에 의하여 $\mathrm{MnS}$ $\mathrm{MSs}$ 를 합성하였다. 같은 방법으로, 표면개질 된 $\mathrm{CNT}$ 를 첨가하여 $\mathrm{MnS} / \mathrm{CNT} \mathrm{HSs}$ 를 합성하였다. 이는 $\mathrm{MnS}$ 낮은 전기 전도성을 향상시켜, 향상된 전기화학적 특성을 구현 하기 위한 것이다. 합성된 $\mathrm{MnS} \mathrm{MSs}$ 는 직경이 $1 \mu \mathrm{m}$ 를 갖 는 매우 균일한 구형체이다. 균일한 구형체의 표면에는 나노로드들이 수직 배열되어 있다. $\mathrm{MnS} / \mathrm{CNT} \mathrm{HSs}$ 는 합성 시에 표면개질된 $\mathrm{CNT}$ 카르복실기의 음전하와 PVP의 상 호 작용에 의하여 hollow 구조체가 형성되었다. $\mathrm{MnS} / \mathrm{CNT}$ $\mathrm{HSs}$ 는 나노로드들이 일정한 방향으로 균일하게 배열된 나 노로드들이 껍질을 이루고 있으며 나노로드 사이에는 CNT 가 네트워크를 이루고 있다. 이를 이용하여 제조된 전극은 $\mathrm{C} / 10$ 의 전류 밀도에서 측정된 리튬이온과의 전기화학적 특 성 평가 결과, 10 사이클의 충·방전 후 약 $365 \mathrm{mAhg}^{-1}$ 의 가 역적인 용량 특성을 보였다. $\mathrm{MnS} \mathrm{MSs}$ 전극과 비교하면 향상된 결과를 보여준다. 이는 고전도성의 $\mathrm{CNT}$ 와 복합체 를 이루고 있기 때문이다.

\section{Acknowledgment}

이 논문은 2013년도 미래창조과학부의 재원으로 한국 연구재단의 중견핵심사업으로 수행된 연구임(2012R1A2A2 A01045382).

\section{REFERENCES}

1. B. Huang, K. Tai, and S. J. Dillon, "Structural Evolution of $\alpha-\mathrm{Fe}_{2} \mathrm{O}_{3}$ Nanowires during Lithiation and Delithiation," $J$. Power Sources, 245 308-14 (2014).

2. A. K. Rai, J. Gim, L. T. Anh, and J. Kim, "Partially Reduced $\mathrm{Co}_{3} \mathrm{O}_{4} /$ Graphene Nanocomposite as an Anode Material for Secondary Lithium Ion Battery," Electrochim. Acta, 100 6371 (2013).

3. W. Liu, Y. Sun, C. Feng, C. Jin, and F. Xiao, "Ni/amorphous $\mathrm{CuO}$ Core-Shell Nanocapsules with Enhanced Electrochemical Performances," J. Power Sources, 245 256-261 (2014).

4. J. M. Yan, H. Z. Huang, J. Zhang, Z. J. Liu, and Y. Yang, "A Study of Novel Anode Material $\mathrm{CoS}_{2}$ for Lithium Ion
Battery," J. Power Sources, 146 246-69 (2005).

5. C. Dong, X. Zheng, B. Huang, and M. Lu, "Enhanced Electrochemical Performance od FeS Coated by Ag as Anode for Lithium-Ion Batteries," Appl. Surf. Sci., 265 114-19 (2013).

6. D. Zhang, X. L. Wang, Y. J. Mai, X. H. Xia, C. D. Gu, and J. P. Tu, "Enhanced Electrochemical Performance of $\mathrm{FeS}_{2}$ Synthesized by Hydrothermal Method for Lithium Ion Batteries," J. Appl. Electrochem., 42 263-69 (2012).

7. W. Luo, Y. Xie, C. Wu, and F. Zheng, "Spherical $\mathrm{CoS}_{2} @$ Carbon Core-Shell Nanoparticales: One-Pot Synthesis and Li Storage Property," Nanotechnology, 19 [7] 075602 (2008).

8. D. Zhang, G. Wu, J. Xiang, J. Jin, Y. Cai, and G. Li, "Synthsis and Electrochemical Performance of Bud-Like $\mathrm{FeS}_{2}$ Microspheres as Anode Materials for Rechargeable Lithium Batteries," Mater. Sci. Eng. B, 178 [8] 483-88 (2013).

9. Y.-D. Ko, J.-G Kang, J.-G. Park, S. Lee, and D.-W. Kim, "Self-supported $\mathrm{SnO}_{2}$ Nanowire Electrodes for High-Power Lithium-Ion Batteries," Nanotechnology, 20 [45] 455701 (2009).

10. Y. Yao, M. T. McDowell, I. Ryu, H. Wu, N. Liu, L. Hu, W. D. Nix, and Y. Cui, "Interconnected Silicon Hollow Nanospheres for Lithium-Ion Battery Anode with Long Cycle Life," Nano Lett., 11 [7] 2949-54 (2011).

11. J. Park, G.-P. Kim, H. N. Umh, I. Nam, S. Park, Y. Kim, and J. Yi, " $\mathrm{Co}_{3} \mathrm{O}_{4}$ Nanoparticles Embedded in Ordered Mesoporous Carbon with Enhanced Performance as an Anode Material for Li-Ion Batteries," J. Nanopart. Res., 151943 (2013).

12. C. Xu, D. Nie, H. Chen, G. Zhao, and Y. Liu, "Fabrication of Cobalt Hollow Microspheres Via a PVP-Assisted Solvothermal Process," Mater. Lett., 110 87-90 (2013).

13. Q. Xia, X. Chen, K. Zhao, and J. Liu, "Synthesis and Characterizations of Polycrystalline Walnut-Like CdS Nanoparticle by Solvothermal Method with PVP as Stabilizer," Mater. Chem. Phys., 111 98-105 (2013).

14. Y. -H. Jin, K.-M. Min, S.-D. Seo, H.-W. Shim, and D.-W. Kim, "Enhanced Li Storage Capacity in 3-Nm-diameter $\mathrm{SnO}_{2}$ Nanocrystals Firmly Anchored on Multiwalled Carbon Nanotubes," J. Phys. Chem. C, 115 22062-67 (2011).

15. Y. Liu, Y. Qiao, W.-X. Zhang, Z. Li, X.-L. Hu, L.-X. Yuan, and Y.-H. Huang, "Coral-Like $\alpha$-MnS Composites with NDoped Carbon as Anode Materials for High-Performance Lithium-Ion Batteries," J. Mater. Chem., 2224026 (2012). 